\title{
A(s) voz(es) de Ellen Oléria: multiplicidade, interseccionalidade e resistência em uma carreira musical ${ }^{12}$
}

\author{
Las voces de Ellen Oléria: multiplicidad, interseccionalidad y resistencia \\ en una carrera musical
}

\author{
The voices of Ellen Oléria: multiplicity, intersectionality and resistance \\ in a musical career
}

\author{
Adélia de Souza Procópio ${ }^{3}$ \\ Mara Coelho de Souza Lago ${ }^{4}$ \\ Vânia Beatriz Müller 5
}

\begin{abstract}
Resumo
Neste trabalho, discutimos como se dão as dinâmicas identitárias na construção da carreira, no discurso musical e declarações públicas da cantora, compositora, instrumentista, apresentadora e atriz Ellen Oléria. A artista tem sido reconhecida por sua postura afirmativa como mulher, negra, lésbica, gorda, latina e vegana e por seu discurso antidiscriminatório. Procuramos analisar alguns posicionamentos políticos no discurso de Ellen Oléria em seus pronunciamentos públicos, bem como a forma como suas canções abordam questões de gênero, raça, sexualidade e classe. A pesquisa foi informada por epistemologias feministas. Além disso, propusemos uma abordagem interdisciplinar, integrando referenciais teóricos e metodológicos de disciplinas das ciências humanas. Em termos metodológicos, nos utilizamos da Análise do Discurso (AD), de orientação da escola francesa - em especial Michel Pêcheux e na leitura de sua obra feita por Eni Orlandi - e também de teorizações de Michel Foucault acerca do funcionamento do discurso e de sua abordagem. No texto, inicialmente, apresentamos uma discussão teórica acerca das identidades e abordamos as afirmações sobre múltiplas identidades culturais de Oléria. Em seguida, enfocamos os posicionamentos sobre raça e racismo da cantora, utilizando teorias sobre interseccionalidades para a compreensão de como diversos marcadores sociais, como raça, gênero, classe e sexualidade, se inter-relacionam na vivência e produção de Ellen. Após isso, abordamos a obra de Ellen Oléria como uma forma de afirmação, ou seja, como música identitária e como esta pode atuar como uma "voz" que "representa" grupos subalternizados e, ao mesmo tempo, constrói uma autorrepresentação da cantora. Por fim, discutimos como as intersecções dos múltiplos processos discriminatórios experimentados por Oléria representam também possibilidades de resistência e de transformação da ordem social por meio de sua música.
\end{abstract}

Palavras-Chave: gênero; interseccionalidade; música; resistência; sexualidade.

\footnotetext{
${ }^{1}$ Artigo apresentado no Simpósio Temático Saberes de Desaprendizagens, Artes, Gênero e Sexualidade, durante o II Seminário Latino-Americano de Estudos em Cultura - SEMLACult em Foz do Iguaçu/PR, Brasil, 2018.

${ }^{2}$ O presente trabalho foi realizado com apoio da Coordenação de Aperfeiçoamento de Pessoal de Nível Superior - Brasil (CAPES) - Código de Financiamento 001.

${ }^{3}$ Mestra em Sociologia; Doutoranda no Programa em Pós-Graduação Interdisciplinar em Ciências Humanas da Universidade Federal de Santa Catarina; Florianópolis, Santa Catarina, Brasil; adeliasprocopio@hotmail.com.

${ }^{4}$ Doutora em Psicologia da Educação; Professora na Universidade Federal de Santa Catarina; Florianópolis, Santa Catarina, Brasil; maralago7@gmail.com.

5 Doutora Interdisciplinar em Ciências Humanas; Professora na Universidade do Estado de Santa Catarina; Florianópolis, Santa Catarina, Brasil; vabem@yahoo.com.br.
} 


\title{
Resumen
}

En este trabajo, discutimos cómo se dan las dinámicas identitarias en la construcción de la carrera, en el discurso musical y declaraciones públicas de la cantante, compositora, instrumentista, presentadora y actriz Ellen Oléria. La artista ha sido reconocida por su postura afirmativa como mujer, negra, lésbica, gorda, latina y vegana y por su discurso antidiscriminatorio. Se trata de analizar algunos posicionamientos políticos en el discurso de Ellen Oléria en sus pronunciamientos públicos, así como la forma en que sus canciones abordan cuestiones de género, raza, sexualidad y clase. La investigación fue informada por epistemologías feministas. Además, propusimos un enfoque interdisciplinario, integrando referenciales teóricos y metodológicos de disciplinas de las ciencias humanas. En términos metodológicos, utilizamos el Análisis del Discurso (AD), de orientación de la escuela francesa -en especial Michel Pêcheux y en la lectura de su obra hecha por Eni Orlandi- y también de teorizaciones de Michel Foucault acerca del funcionamiento del discurso y de su interpretación enfoque. En el texto, inicialmente, presentamos una discusión teórica acerca de las identidades y abordamos las afirmaciones sobre múltiples identidades culturales de Oléria. En seguida, enfocamos los posicionamientos sobre raza y racismo de la cantante, utilizando teorías sobre interseccionalidades para la comprensión de cómo diversos marcadores sociales, como raza, género, clase y sexualidad, se interrelacionan en la vivencia y producción de Ellen. Después de eso, abordamos la obra de Ellen Oléria como una forma de afirmación, o sea, como música identitaria y cómo ésta puede actuar como una "voz" que "representa" grupos subalternizados y, al mismo tiempo, construye una autorrepresentación de la cantante. Por último, discutimos cómo las intersecciones de los múltiples procesos discriminatorios experimentados por Oléria representan también posibilidades de resistencia y de transformación del orden social por medio de su música.

Palabras claves: género; interseccionalidad; música; resistencia; sexualidad.

\begin{abstract}
In this work, we discuss how the identity dynamics in the construction of the career, in the musical discourse and public declarations of the singer, composer, instrumentalist, presenter and actress Ellen Oléria are given. The artist has been recognized for her affirmative posture as a woman, black, lesbian, fat, latin, and vegan, and for her antidiscriminatory discourse. We try to analyze some political positions in Ellen Oléria's speech in her public pronouncements, as well as the way her songs address issues of gender, race, sexuality and class. The research was informed by feminist epistemologies. In addition, we proposed an interdisciplinary approach, integrating theoretical and methodological references of disciplines of the human sciences. In methodological terms, we used the Discourse Analysis (DA), the orientation of the French school - especially Michel Pêcheux and the reading of his work by Eni Orlandi - and also the theorizations of Michel Foucault about the functioning of the discourse and its approach. In the text, initially, we present a theoretical discussion about identities and approach the affirmations about multiple cultural identities of Oléria. Next, we focus on the singer's stance on race and racism, using intersectionality theories to understand how various social markers, such as race, gender, class, and sexuality, interrelate in Ellen's experience and production. After this, we approach Ellen Oléria's work as a form of affirmation, that is, as identity music and how it can act as a "voice" that "represents" subalternized groups and, at the same time, builds a self-representation of the singer. Finally, we discuss how the intersections of the multiple discriminatory processes experienced by Oléria also represent possibilities of resistance and transformation of the social order through their music.
\end{abstract}

Keywords: gender; intersectionality; music; resistance; sexuality.

\section{Introdução}

Ellen Oléria é cantora, compositora, instrumentista, produtora e atriz. Viveu sua infância em uma região periférica de Taguatinga-DF. Seus primeiros contatos com a música se deram de forma autodidata e, posteriormente, por sua participação como cantora em uma igreja Batista. Depois passou a fazer shows em casas noturnas. É formada em Artes Cênicas pela Universidade de Brasília (DICIONÁRIO CRAVO ALBIN). Ganhou vários prêmios, como o Prêmio Sesc de 
Música e o Festival Interno da Música Candanga (Irlam R. LIMA, 2009). Ellen era considerada pela crítica musical local a maior expoente da música brasiliense (Fernanda ALCÂNTARA, 2013) até se tornar nacionalmente conhecida ao vencer a edição 2012 do reality show The Voice, exibido pela Rede Globo. Após isso, Oléria gravou mais dois CDs (já havia gravado dois anteriormente) e passou a fazer shows em todo o Brasil e no exterior. Como compositora da maioria das músicas que executa, a artista mistura ritmos brasileiros com soul music e levadas de jazz. Em suas canções, Ellen Oléria busca refletir a realidade com a qual convive (LIMA, 2009). Desde o início de sua carreira e, cada vez mais, Ellen tem sido reconhecida como uma artista que tem uma postura e uma música que afirmam sua condição de mulher, negra, lésbica, gorda, latina, vegana (O GLOBO, 2013). Oléria tem se tornado conhecida também por seu discurso antidiscriminatório. Assim, a artista mobiliza uma série de identidades culturais e um posicionamento afirmativo quanto a desigualdades sociais diversas.

Neste texto, apresentamos uma análise sobre as dinâmicas identitárias na construção da carreira e no discurso musical de Ellen Oléria. Priorizamos o uso de referenciais teóricos póscoloniais e/ou produzidos no Sul Global. Entendendo aqui pós-colonialismo como definido por Boaventura Santos (2004), como um conjunto de correntes teóricas e analíticas, principalmente nos estudos culturais, que têm em comum darem primazia às relações desiguais entre o Norte e o Sul na explicação do mundo contemporâneo. Assim, o pós-colonialismo é uma perspectiva que concebe que, a partir das margens ou das periferias, as estruturas de poder e saber são mais visíveis. Consideramos que esse referencial teórico seja o mais adequado porque problematiza as relações entre poder e subjetividade, bem como entre poder e desigualdades, ligadas a gênero, sexualidades, raça, processos de colonização, entre outros. Assim, estas teorias nos permitem analisar a produção de uma cantora que apela para marcadores identitários diversos e se coloca como voz periférica, ou ligada a grupos tradicionalmente oprimidos, mas que contesta a ordem vigente com sua atuação.

Mais especificamente, procuramos analisar alguns posicionamentos políticos no discurso de Ellen Oléria em entrevistas ou outros tipos de declarações públicas, bem como a forma como suas canções abordam questões identitárias ligadas a gênero, raça, sexualidade e classe. Para tanto, no primeiro tópico, apresentamos uma discussão acerca das identidades e algumas afirmações identitárias de Oléria; no segundo, enfocamos os posicionamentos sobre raça e racismo da cantora, utilizando teorias sobre interseccionalidades para a compreensão de como diversos marcadores sociais como raça, gênero, classe e sexualidades se interrelacionam na vivência e produção de Ellen; no terceiro, abordamos a produção de Ellen Oléria como uma forma de afirmação, ou seja, como música identitária e como esta pode atuar como uma "voz" 
que representa grupos subalternizados; por fim, discutimos como as intersecções de processos discriminatórios experimentados por Oléria representam também possibilidades de resistência.

\section{Estratégias metodológicas}

A pesquisa que deu origem a este texto, foi informada por epistemologias feministas, o que significa fazer da análise uma reflexão politizada, ressaltando as vivências e realizações de mulheres e discutindo as relações de gênero e poder, rompendo, assim, com muitos silenciamentos (Laila ROSA; et al, 2013). Além disso, propusemos uma abordagem interdisciplinar, integrando referenciais teóricos e metodológicos das áreas de antropologia, sociologia, letras, musicologia, etnomusicologia, história e filosofia. A “interdisciplinaridade não configura uma teoria ou um método novo: ela é uma estratégia para compreensão, interpretação e explicação de temas complexos" (Maria Cecília MINAYO, 2010, p. 437, apud Carlos GARCIA JR e Marta VERDI, 2015).

Em termos metodológicos, nos utilizamos da Análise do Discurso (AD), de orientação da escola francesa (em especial Michel Pêcheux e da leitura de sua obra feita por Eni Orlandi) e também de teorizações de Michel Foucault acerca do funcionamento do discurso e de sua abordagem.

De acordo com Foucault (1996), estudar os discursos é desvendar a relação entre as práticas discursivas e os poderes que as permeiam; procurar, não as representações que estão por trás deles, mas suas estratégias e os procedimentos pelos quais são instaurados, os interesses a que servem, expor os mecanismos pelos quais operam, a distribuição dos sujeitos que falam nos diferentes tipos de discurso e a apropriação destes por certas categorias de sujeitos.

A Análise do Discurso (AD) visa fazer compreender como os objetos simbólicos produzem sentidos, descrevendo as condições sócio-históricas e ideológicas do surgimento destes. Para a AD, o que importa não é "o quê" é dito (ou escrito, cantado, etc.), mas o "como". (Eni ORLANDI, 2015). Para Michel Pêcheux (2015), o contato do histórico com o linguístico constitui a materialidade específica do discurso. Segundo o autor, os acontecimentos discursivos ocorrem ou não segundo as construções discursivas nas quais se encontram inscritos os enunciados que sustentam esses acontecimentos. Assim, a AD tem como objeto explicitar montagens e arranjos sócio-históricos de constelações de enunciados. Todo discurso se relaciona com outros. $\mathrm{Na}$ abordagem do discurso a/o analista "observando as condições de produção e verificando o funcionamento da memória, [...] deve remeter o dizer a uma formação discursiva (e não outra) para compreender o que ali está dito.” (ORLANDI, 2015, p. 43).

Quanto aos procedimentos e corpus de pesquisa, foram selecionadas letras de canções, compostas ou interpretadas por Ellen Oléria. Também foram levantadas reportagens sobre a 
cantora e entrevistas por ela concedidas a jornais e revistas, postagens nas redes sociais Facebook e Twitter, textos escritos por Oléria, textos de seu site artístico, fotos em revistas, encartes e capas de discos. Também pesquisamos material em vídeo, como shows, participações em programas televisivos em DVD e no YouTube. Além disso, fizemos uma caracterização da cantora em termos étnico-racial, geracional, de classe social e dos fatos biográficos mais relevantes, tendo em vista uma perspectiva interseccional.

\section{As identidades de Ellen Oléria}

Em entrevista com Ellen Oléria afirma-se que "debates e provocações sobre a violência social - assim como sobre o racismo e a questão de gênero - tornaram-se marcas da cantora, que passa a ser conhecida não somente por conta do forte timbre, mas igualmente pelo discurso de combate à intolerância (Diego LEON, 2015). No próprio site de Ellen, sua equipe a apresenta como "representativa para as periferias e comunidade negra do brasil (sic) ao combinar suas diversas identidades de resistência - jovem, compositora, negra periférica, lésbica" (SITE DE ELLEN OLÉRIA, 2015). Dessa forma, os posicionamentos públicos e as canções de Oléria suscitam reflexões sobre a identidade.

Desde o final do século XX, a questão da identidade tem sido extensamente discutida na teoria social. Argumenta-se que as identidades modernas estão entrando em colapso. Nesse raciocínio, uma mudança estrutural tem transformando as sociedades modernas de forma que há uma fragmentação dos referenciais culturais de classe, gênero, sexualidade, etnia, raça e nacionalidade, que, supostamente, antes ofereciam sólidas localizações para os indivíduos. Diante disso, as identidades pessoais também estariam mudando, causando um abalo na ideia que as pessoas têm de si como sujeitos integrados. Assim, há um deslocamento ou descentração duplos do sujeito: de seu lugar no mundo social e cultural e de si mesmos. Isso representa uma “crise de identidade". Nessa concepção, as identidades não são unificadas, mas sim, cada vez mais fragmentadas e fraturadas (HALL, 2011).

Com relação às discussões acerca da fragmentação das identidades, Mara Lago (1999) considera que vários cientistas sociais têm acreditado que na pós-modernidade os indivíduos são portadores de inúmeras identidades. Para autora, há uma confusão entre a fragmentação de identidades culturais e a fragmentação do sujeito em variadas identidades pessoais.

Na condição pós-moderna, diante do esfacelamento dos projetos unitários de sociedade, acontece a fragmentação e exacerbação das identidades de grupos sociais em lutas reivindicatórias, competindo por espaços, pelo acesso a bens materiais e culturais. Contudo, de acordo com Lago (1999), a identidade, como representação ficcional do eu, procura dar conta 
das contradições do sujeito, organizando-as numa história coerente. Assim, a identidade pressupõe uma história de vida com um mínimo de coerência e unidade, o que se contrapõe às visões de sujeito como portador de múltiplas identidades. Para a autora, há semelhanças entre os processos de construção de identidades pessoais, pelos sujeitos, e identidades culturais, pelos grupos sociais. Ambas se constroem no campo social, nas relações, e resultam de relações contrastivas e de identificação entre eu, nós, outro(s) (LAGO, 2004). Assim, quando no título deste tópico uso "as identidades de Ellen Oléria", aludo às referências identitárias culturais que a interpelam e às posições de sujeito que a artista pode assumir, e não a inúmeras identidades pessoais fragmentadas que ela teria.

Stuart Hall (2000) define o termo identidade como o ponto de encontro ou de sutura, entre, por um lado, os discursos e as práticas que tentam nos "interpelar", ou nos convocar para que assumamos nossos lugares como os sujeitos sociais de discursos particulares e, por outro lado, os processos que produzem subjetividades, que nos constroem como sujeitos aos quais se pode "falar". As identidades são, segundo o autor, pontos de apego temporário às posições de sujeito que as práticas discursivas constroem para nós. As identidades são específicas quando aos locais históricos e institucionais nos quais são produzidas e quanto às formações e práticas discursivas, e estratégias de sua construção. Assim, Hall defende o uso de um conceito de identidade que não seja essencialista, mas sim estratégico e posicional.

Tomaz Tadeu da Silva (2000) relaciona identidade com diferença e afirma que ambas são mutuamente determinadas. $\mathrm{O}$ autor aponta que identidade e a diferença são processos de produção social, que envolvem relações de poder. Identidade e diferença implicam operações de incluir, excluir, classificar e hierarquizar. Assim: "A afirmação da identidade e a enunciação da diferença traduzem o desejo dos diferentes grupos sociais, assimetricamente situados, de garantir o acesso privilegiado aos bens sociais" (p. 81). O autor aponta que a identidade e a diferença são criações sociais e culturais, criadas por meio da linguagem, pois precisam ser nomeadas e ativamente produzidas, pois não são naturais ou transcendentais. $\mathrm{O}$ caráter afirmativo, relacional, estratégico e posicional das identidades remete à noção de política das identidades. No contexto desta, cada movimento apela para a identidade social de suas/seus sustentadoras/es, por exemplo, o feminismo apela às mulheres, as lutas raciais às/aos negras/os.

Assim, há uma identidade para cada movimento (HALL, 2011). Ella Shohat e Robert Stam (2006) afirmam que vivemos em uma atmosfera política dominada pelas políticas das identidades e as questões de autorrepresentação, questões sobre as tensões políticas a respeito de quem fala, quando, como e em nome de quem. As políticas das identidades lutam, em 
especial, pela autorrepresentação de comunidades marginalizadas, pelo direito de "falar por si mesmo".

Como dito no início deste tópico, Ellen Oléria, em suas afirmações públicas e em sua obra, mobiliza diversas identidades sociais: negra, mulher, lésbica, gorda, vegana, de origem periférica. Seus posicionamentos vão ao encontro da política de vários movimentos sociais, com os quais Oléria frequentemente dialoga. A artista se manifesta em prol de diversas causas políticas: combate ao racismo, direitos dos animais, proteção às crianças e adolescentes, contra a redução da maioridade penal, seja por meio de redes sociais, em seu site, ou nas entrevistas que concede. Como exemplo disso, em uma postagem no Twitter em 26/08/2015, diz "o especismo é um retrocesso. animais não são mercadoria. vergonha da categoria que se intitula humana. \#pelavida \#pelosbichos”. Ellen Oléria também participa de eventos políticos, como a mediação que fez da mesa da Comissão Extraordinária de Direitos Humanos e Minorias (em dezembro de 2013), da campanha Rio Sem Preconceito. Ellen foi uma das atrações do festival “Todo Mundo tem Direitos", ocorrido em 10/12/2015, pelo dia internacional dos direitos humanos. A respeito do evento Oléria postou no Facebook em 15/12/2015: "tô ligada que a gente precisa fazer muito mais pra parar a máquina do racismo, por ora queremos celebrar o que todo dia tentou nos matar e não conseguiu". Esta última afirmação ilustra como Ellen Oléria presta apoio político a diversas causas e grupos subalternizados, mas, na maioria das vezes, seus apelos estão relacionados à sua própria experiência, a situações que ela vivencia. Avtar Brah (2006) afirma que experiência é um lugar de contestação: um espaço discursivo onde posições de sujeito e subjetividades diferentes são inscritas, reiteradas ou repudiadas. Nesse sentido, pode-se compreender a frequente exposição de Oléria de elementos de sua vida pessoal, sobretudo no que toca à sua sexualidade.

Na época da escrita deste texto, a foto de perfil do Twitter de Ellen possui um filtro com a figura do espelho de vênus duplo e cruzado, como referência à visibilidade lésbica. Oléria faz constantes declarações públicas de amor à mulher com quem é casada, Poliana Martins, como, por exemplo, nessa postagem:

hoje eh o aniversário da minha musa. minha amiga, minha amante. essa pretinha que eh feita da matéria do sol. minha pequena oxum...[...] quero viver contigo incontáveis verões, até o fim de tudo. obrigada por partilhar comigo esse século. te amo, dona da palavra! (Facebook 12/01/2015).

Oléria também posta fotos do cotidiano das duas, incluindo a cerimônia de seu casamento. Perguntada em uma entrevista sobre como se porta diante da intolerância quanto à homossexualidade, Ellen responde: "Eu ligo o "f...-se"! Mas esse "f...-se" precisa ser bem consciente. Eu quero dizer para todo mundo que meu amor por essa mulher me transforma. Eu 
quero dizer que ser afrobrasileira, ser negra, me faz uma mulher feliz" (LEON, 2015). A vivência lésbica também se manifesta em suas canções. Nelas, Ellen se dirige às mulheres como objeto amoroso, o que se expressa, por exemplo, no uso do pronome “ela", em Geminina: "Ela me faz sofrer, ela me faz chorar", ou em outras referências ao feminino, como na música Solta na vida: "Há o que me deixa ainda emocionada/ O vento, a saia/ O vento subindo a saia rodada/ E a blusinha dela tomara que caia".

As desigualdades vivenciadas por mulheres são também tratadas por Ellen Oléria, como em Córrego Rico: “Tia Preta traz a peta (...) / tia Preta toma o café/ Tia Preta esconde a tristeza, tia Preta mais uma mulher". E em outra letra, Mandala: “Antonina, minha filha/Cuide da sua vida/Não deixe parecer com a minha/Eu fiz silêncio demais". A artista aborda afirmativamente as posições e condições das mulheres, inclusive a sua, nas relações de gênero. De acordo com Rosi Braidotti (2004), o fracasso de uma definição do sujeito, pressuposto masculino, é a grande oportunidade para aquelas/es que, como as mulheres, tem sido historicamente privados de seu direito à autodeterminação. É preciso que as mulheres, em especial, possam estabelecer uma diferença e lograr que esta diferença se perceba concretamente. Isso se expressa também na obra de Ellen Oléria. O feminismo está presente em suas letras, principalmente em Antiga Poesia

(...) Força feminina, rá rá Escrevo sem ter linha

Escrevo torto mesmo (...) Pra seu desespero (...) A minha poesia é poesia combativa Eu entendi seu livro, eu entendi sua língua Agora minha língua, minha rima eu faço Eu já me fiz sozinha E eu tenho mais palavras Da boca escorrendo(...)

A planta é feminina, a luta é feminina

La mar, la sangre y mi América Latina O meu desejo é que o seu desejo não me defina (...) Salve! Negras dos sertões, negras da Bahia (...)

Salve! Nortistas, caribenhas, clandestinas

Salve! Negras da América Latina A baixa auto-estima da Dona Maria

Da sua prima, da sua filha e sua vizinha Isso me intriga, isso me instiga

E cê não entendeu o que significa feminista

Aqui não tem drama ou gente inocente

Aqui tem mulher firme arrebentando as suas correntes A vida toda alguma coisa tentou me matar e eu me refiz (...)

Salve! Permanecemos vivas (...)

Nesta canção, entendemos que Oléria expressa o que Cláudia Pons Cardoso (2014) chama de "tornar-se negra", ou seja, um processo social de construção de identidades, de 
resistência política, pois recusa ser definida pelo olhar do outro. Isso significa sua autodefinição, a valorização e a recuperação da história e do legado cultural negro, traduzindo um posicionamento político ao exercer o papel de protagonista no enfrentamento do racismo. Mas a letra de Antiga Poesia também é um explícito posicionamento feminista e uma exaltação da resistência e experiência das mulheres. Para Braidotti (2004), a experiência é a noção central que sustenta o projeto feminista, o que Adrienne Rich (apud BRAIDOTTI, 2004) expressa na ideia de "política de localização". Esta significa que a produção teórica é parcial, ou seja, não é abstrata, universal, objetiva e nem indiferente. Em outras palavras, a visão é posicional, ou estreitamente vinculada com o lugar da enunciação. A defesa feminista dos "saberes situados", citando Donna Haraway (apud BRAIDOTTI, 2004) se choca com a generalidade abstrata do sujeito patriarcal. Isso se expressa quando Ellen Oléria afirma: "pra saber de nossas histórias, tivemos que cavar bem fundo. só eu sei o que sou e, como disse bell hooks, só eu conheço o corpo que é meu" (Ellen OLÉRIA, 2014).

\section{Interseccionalidade}

De acordo com Alcântara (2013), Ellen Oléria mostra suas raízes e desponta como uma notável celebridade negra. As questões raciais e o combate ao racismo também são marcados em seus posicionamentos e canções, como em Ato 2: "Basalto que emana dos meus poros/ Minha consciência-pedra nesse instante (...)/A minha consciência negra"; e Testando, em que fala especialmente sobre o racismo velado brasileiro (Bia CARDOSO, 2011):

(...)A minha palavra é afiada e contamina Minha ginga, meu jeito, minha voz que vem do gueto Minha raça, minha cara, tua cara à tapa O meu cabelo crespo

Não ponho na chapa, aguenta minha marra Teu cartão não me paga Minha ancestralidade no peito eu não tô te vendendo.(...) Andando na rua de noite muita gente branca já fugiu de mim A minha ameaça não carrega bala, mas incomoda o meu vizinho O imaginário dessa gente dita brasileira é torto Grita pela minha pele. Qual será o meu fim? Eu não compactuo com esse jogo sujo Grito mais alto ainda e denuncio esse mundo imundo A minha voz transcende a minha envergadura Conhece a carne fraca? Eu sou do tipo carne dura

Ellen Oléria também apela para sua origem, de uma região urbana periférica. Em suas palavras: "Canto o universo de uma negra, lésbica, criada no Chaparral, região entre Taguatinga e Ceilândia" (LIMA, 2009). Ellen diz ainda que cresceu "em um ambiente brutal" (OLÉRIA, 2014). Questões de classe social também estão presentes em suas canções, como em Senzala 
(conhecida como Feira da Ceilândia). Nela, Ellen retrata o cotidiano e os sentimentos que perpassam as/os frequentadoras/es de uma feira, além de compará-la ao elitismo preconceituoso dos shoppings centers (CARDOSO, 2011).

\section{(...) lambada som da hora na senzala.(...) Mas o que você precisa mais, na feira não se pode encontrar: razão, consciência, senso, inteligência, uma cabeça pra pensar. Isso só no shopping lá do centro você vai achar, se tiver dinheiro pra comprar, boa aparência pra entrar}

Assim, Oléria se posiciona quanto a diversas questões, como gênero, raça, classe, sexualidade, vivência na periferia, que refletem sua experiência e também desigualdades sociais. Mas essas não são dimensões separadas de sua existência, como demonstra boa parte da teoria recente sobre gênero. De acordo com Cláudia L. Costa e Eliana Ávila (2005), quando vozes de mulheres oprimidas se tornaram proeminentes, a dicotomia de gênero deixou de ser o centro da discussão sobre diferença, que passou a ser focada na exploração das diferenças entre as mulheres, o que marcou o pensamento e a prática feminista na década de 1980. No Brasil, Lélia González (1988), na década de 80, já defendia a articulação entre as categorias de raça, classe, sexo e poder para desmascarar as estruturas de dominação de uma sociedade (CARDOSO, 2014). De acordo com Adriana Piscitelli (2008), no final da década de 1990, emergem as categorias que fazem referência à multiplicidade de diferenciações que, articulando-se a gênero, permeiam o social. Em especial, as categorias de articulação e as interseccionalidades permitem apreender a relação de múltiplas diferenças e desigualdades, para dar conta das interações entre possíveis diferenças presentes em contextos específicos. As autoras que trabalham com essas categorias enfatizam que discriminações de raça e de gênero não são fenômenos mutuamente excludentes. Por isso, é necessário a identificação das várias formas de subordinação derivadas da interação entre os dois. Essas discriminações causam opressões específicas para mulheres negras ao operarem juntas.

Segundo Kimberlé Crenshaw (2002), a interseccionalidade é uma conceituação do problema que busca capturar as consequências estruturais e dinâmicas da interação entre dois ou mais eixos da subordinação. Trata da forma pela qual o racismo, o patriarcalismo, a opressão de classe e outros sistemas discriminatórios criam desigualdades básicas que estruturam as posições relativas de mulheres e de outros grupos, produzindo também o desempoderamento. Para a autora, a interseccionalidade aborda diferenças dentro da diferença (CRENSHAW, 2004). Boa parte das canções de Ellen Oléria trata de mais de um tipo de desigualdade social, como em Solta na Vida: "Patriotismo, civismo, nacionalismo/ Xenofobismo, machismo, 
racismo/ Um abismo chama outro abismo". Mas, além disso, a artista já se pronunciou a respeito das intersecções das opressões que vivencia:

Passei a vida apagando da memória os episódios de racismo que sofri” [...]. Penso que sou uma espécie de intersecção de processos discriminatórios. Sou mulher, lésbica, gorda e negra. Nenhum é mais expressivo que o outro, cada um tem sua especificidade. Mas eu posso não dizer que sou lésbica ou me passar por homem [...] o recorte econômico também não precisa ser exposto, e posso perder peso até, mas não posso esconder minha negritude. Sou negra, aqui ou em qualquer lugar (OLÉRIA, 2014).

Nesse trecho, Oléria expressa a conexão das opressões que vivencia, mas enfatiza a questão racial. Para Brah (2006) processos de racialização do gênero, classe e sexualidade são historicamente específicos. No entanto, "raça" ainda atua como um marcador aparentemente inerradicável de diferença social (p. 331). Para Aníbal Quijano (2002), no atual padrão de poder mundial, a ideia de "raça" funciona como um dos elementos mais importantes da colonialidade do poder, ou seja, como fundamento do padrão universal de classificação social básica e de dominação social. Na América Latina, em especial, o discurso de que somos sociedades multiétnicas e multiculturais não implica a real descolonização da sociedade nem do Estado, e muitas vezes, serve para reforçar o racismo e deslegitimar as lutas sociais contra essa forma de dominação. Acerca do racismo, Ellen Oléria afirma:

O racismo não é uma doença (...) é um mal que é real, que alguns entre nós insistem em negar (...) Todo o nosso projeto de nação foi pautado em cima do especismo, do sexismo, misoginia e classismo. E fundamentalmente de racismo, isso é real e está no imaginário das pessoas (Pedro SANCHES, 2013).

À análise de Quijano, María Lugones (2014) acrescenta que, nas situações coloniais presentes na primeira modernidade, houve a construção dos sujeitos coloniais nas tensões criadas pela imposição brutal do sistema moderno colonial de gênero. Para a autora, a colonialidade do gênero ainda permanece na intersecção de gênero/classe/raça como construtos centrais do sistema de poder capitalista mundial. Também Lélia Gonzalez, como uma intelectual pós-colonial, em texto de 1988, já propunha a abordagem interligada do racismo, colonialismo, imperialismo e seus efeitos. A autora enfocava as histórias de resistência e luta dos povos colonizados contra as violências geradas pela colonialidade do poder, assinalando a história da dinâmica cultural de adaptação, resistência, reinterpretação e criação de novas formas afrocentradas. De acordo com a autora, no Brasil prevalece o racismo disfarçado, fundamentando concepções de "miscigenação", "assimilação" e "democracia racial”, o que impossibilita a consciência do racismo (CARDOSO, 2014).

Abordar as questões raciais e de gênero, em suas intersecções internas e com outras relações sociais, não significa considerar apenas as opressões. As intersecções também produzem possibilidades de resistências. Para Chandra Mohanty (2008), no discurso acadêmico 
feminista ocidental há a produção da "mulher do terceiro mundo" como o "Outro", um sujeito monolítico singular. Nesse discurso, há a pressuposição de "mulheres" como um grupo já constituído e coerente, oprimido e subordinado, com interesses idênticos, sem importar a classe social, as questões raciais ou étnicas. Contudo, para a autora, as mulheres, além de diversas, não são simplesmente vítimas, pois resistem, desafiam e subvertem processos de opressão. Também Lugones (2014) enfatiza a resistência como começo da luta política. A autora está interessada na proliferação relacional subjetiva/intersubjetiva de libertação, tanto adaptativa quanto criativamente opositiva. A resistência é a tensão entre a sujeitificação (a formação/informação do sujeito) e a subjetividade ativa. Nas existências colonizadas, racialmente gendradas e oprimidas, as pessoas são diferentes do que o hegemônico as torna. Para Lugones, isso é uma "vitória infrapolítica". Na mesma linha, Cláudia Cardoso (2014) afirma que muitas feministas negras, mulheres de cor, chicanas, vêm atuando como "forasteiras de dentro", ou seja, reinventam definições, delimitam lugares sociais para melhor se posicionarem, realizando sua autodefinição a partir de "narrativas subversivas". A música também pode ser esse espaço de afirmação, contestação e resistência.

\section{Música identitária, vozes e representação}

Brah (2006) aponta que a prática é produtiva de poder. Assim, é também um meio de enfrentar as práticas opressivas do poder. A autora afirma que o mesmo vale para o registro auditivo: "música e outros sons produzem poder" (p. 373). Quanto à importância da música, Ellen Oléria diz "Talvez o fato de estar na música sempre tenha me garantido um trânsito mais tranquilo. Outras mulheres negras vieram antes para garantir meu lugar. Minha geração é feliz porque colhe frutos de uma luta antiga. A música é um espaço legitimado" (OLÉRIA, 2014). Bia Cardoso, em um texto sobre Oléria, assinala que em suas músicas "o sentimento de resistência é visível e presente. [...] seu cotidiano e sua guerra diária está presente em suas letras, para nos lembrar de tantas Ellen Olérias que tristemente ficam em silêncio" (CARDOSO, 2011). A resistência a partir da música de Ellen está presente na letra de Solta Na Vida: “(...) Corro de atrevida, não esmorecida/ (...) Bravura pura em mais de 70 kg/ (...) Pacificamente violenta/ (...) Eu canto pra que eu nunca esqueça".

A respeito da presença da temática da negritude em suas músicas, Ellen Oléria afirma: “essa presença no meu trabalho é indissociável, porque é de um lugar afro que ela emana. [...] essa ancestralidade são os fundamentos das canções que faço. [...]. Não posso negar que a minha música em especial tem muito de raízes: essa sou eu"(LEON, 2015). A vivência negra e as 
origens de Oléria como marcas de sua música aparecem também quando a cantora fala sobre o projeto de seu novo disco, afrofuturista:

\begin{abstract}
passeamos pelos ritmos tradicionais, afrobrasileiros. O álbum fala de raízes, de como as populações afrodiaspóricas têm sobrevivido aos projetos de extinção e massacre com tanta luminosidade, inventividade e criatividade. Passa pelo candomblé, pelas modas de viola, pelo maracatu. [...] Enquanto eu puder cantar e contar nossas histórias, farei isso"(LEON, 2015).
\end{abstract}

A música tem sido um canal privilegiado de afirmação da negritude. De acordo com Shohat e Stam (2006), as colaborações enriquecedoras entre as diversas correntes de música afro-diaspórica - que deram origem a híbridos, por exemplo o samba reggae - oferecem exemplos de um "sincretismo lateral” de certo equilíbrio. A música afro-diaspórica demonstra uma capacidade antropofágica de absorver influências, mesmo as ocidentais, enquanto mantém uma relação cultural com a tradição africana. Sendo a música marcada pelas experiências de quem canta/compõe, é também identitária e uma forma de representação. Para Silva (2000), representar significa dizer: "essa é a identidade". Assim, quem tem o poder de representar tem o poder de definir e determinar a identidade.

Tratando do tema representação, Gayatri Spivak (2010) assinala que há uma relação intrínseca entre o "falar por" (representação política) e o "re-presentar" (como na arte e na filosofia). A autora aponta que os intelectuais ocidentais veem o sujeito subalterno como uma consciência que não "re-presenta" a realidade adequadamente. Spivak critica a representação do sujeito do Terceiro Mundo no discurso ocidental, de forma que o sujeito colonial é constituído como Outro e apenas como objeto de conhecimento e não como sujeito. Para a autora, o intelectual julga poder falar pelo outro e, por meio dele, construir um discurso de resistência. Spivak argumenta que não há nenhum sujeito subalterno irrepresentável que possa saber e falar por si mesmo. O processo de fala se caracteriza por uma posição discursiva, uma transação entre falante e ouvinte. Assim, esse espaço dialógico de interação não se concretiza para o sujeito subalterno que, desinvestido de qualquer forma de agenciamento, não pode falar. A autorrepresentação do sujeito subalterno também não se realiza, pois o ato de ser ouvido não ocorre. Em especial, o sujeito feminino não tem nenhum espaço onde possa falar. Além disso, não pode ser ouvido ou lido. Por isso mesmo, à mulher intelectual, em especial, cabe criar espaços e condições de autorrepresentação, questionando o seu lugar de enunciação.

Por meio das artes, em geral, muitos grupos oprimidos podem combater as representações hegemônicas, contrapondo aos discursos da sociedade patriarcal e do colonialismo uma visão de si mesmos e de sua realidade da perspectiva "de dentro". As artes não representam o "mundo", mas suas linguagens e discursos. O discurso artístico não reflete 
diretamente o real, mas constitui "uma versão mediada de um mundo sócio ideológico que já é texto e discurso" (SHOHAT E STAM, 2006, p. 264). Assim, "a arte é uma representação não tanto em um sentido mimético, mas político, uma delegação de vozes" (p. 265). Para Shohat e Stam (2006), a luta por representação tem correspondência com a esfera política. Comumente, grupos historicamente marginalizados não têm controle sobre sua própria representação e a arte oferece a oportunidade de dar voz a uma polifonia de vozes. De acordo com a autora e o autor, uma voz não coincide exatamente com um discurso, pois este é institucional e transpessoal, já a voz é personalizada, tem a marca da/o autora/r, e constitui uma interação específica de discursos (individuais e coletivos). A concepção de voz se refere à pluralidade: "uma voz nunca é somente uma voz, mas também incorpora um discurso, pois mesmo uma voz individual é a soma de discursos, uma polifonia de vozes" (p. 311). A questão não se resume ao pluralismo, mas ao conjunto múltiplo de vozes, em uma abordagem que procura cultivar e frisar as diferenças culturais enquanto suprime as desigualdades sociais. Propomos aqui que, por meio de sua música e posicionamentos públicos, Ellen Oléria atua como uma "voz", representando grupos sociais tradicionalmente subalternizados, mas também seu "lugar de fala", a partir de suas vivências. Nos termos de Spivak, a artista consegue "falar" e ser ouvida, constrói sua autorrepresentação. Nas palavras de Oléria:

\footnotetext{
Só posso compor, escrever, do meu lugar, a partir das minhas marcas, feitas ao longo da minha passagem pela vida. [...] O que não poderia fazer é negar isso. [...] Sei que minhas opções interferem na cadeia de relações. [...] A gente tem uma ascendência negra, uma orientação sexual, as escolhas afetivas, as músicas que decidimos escutar. [...] Mas a política é sobretudo pessoal (O GLOBO, 2013).
}

\section{Multiplicidade, hibridez e resistência}

Acerca de seu novo disco, no site de Ellen Oléria, afirma-se que "o projeto afrofuturista pretende alimentar a identidade das produções musicais ainda marginalizadas no brasil, como o rap, o funk, as levadas crioladas", e que Oléria

se propõe a explicitar esses ritmos negros na fusão com a mpb. essa fusão é marca registrada do talento ímpar representado pela hibridez afrofuturista da própria oléria, que em suas canções combina o orgânico ao digital, a herança ancestral à projeção do futuro, o mapa holográfico à trilha de chão que leva de volta para casa(SITE DE ELLEN OLÉRIA, 2015).

Aqui se expressa a hibridez da produção artística de Ellen Oléria, o que reflete também a multiplicidade de posições de sujeito que podem ser vivenciadas e mobilizadas pela artista. Para Silva (2000), referindo-se a identidades culturais, a noção de hibridismo, ou seja, a mistura, a conjunção, o intercurso entre diferentes identidades, que são movimentos que complicam e 
subvertem a identidade, problematizam os processos que tendem a conceber as identidades como divididas e segregadas. Silva destaca a instabilidade e precariedade da identidade, que se expressam melhor na possibilidade de "cruzar fronteiras" e de "estar na fronteira", de ter uma identidade ambígua, indefinida, o que é uma poderosa estratégia política de questionamento das operações de fixação da identidade. Na dinâmica das identidades, há ainda a oscilação entre tradição e tradução, conforme aponta Hall (2011). Estão surgindo identidades culturais que retiram seus recursos de diferentes tradições culturais e que são derivadas dos cruzamentos e misturas culturais que emergem em um mundo globalizado.

Na reportagem Ellen Oléria, uma multidão de minorias, afirma-se sobre a artista: "Cada uma de suas identidades fortalece as outras, e assim se rompem os laços de desavenças entre minorias distintas, que é motriz cruel de todos os preconceitos" (SANCHES, 2013). Isso remete à multiplicidade de identidades culturais que Ellen mobiliza. Braidotti (2004) argumenta que na atualidade o que está emergindo é uma identidade múltipla, mutável, composta por representações heterogêneas e heterônomas de gênero, raça e classe, que parte de uma história de assimilações múltiplas e na qual se insiste de modo estratégico. Conforme Shohat e Stam (2006), as identidades complexas e multifacetadas são o objeto das teorias pós-coloniais.

Nessa linha, Lugones (2014) aborda o sujeito na fronteira, ou seja, no ponto de cruzamento de identidades e diferenças múltiplas, o qual é um lugar de opressão, mas também de resistência.

Quero marcar especialmente a necessidade de manter uma leitura múltipla do ente relacional que resiste. [...] a percepção e a habitação múltiplas, a fratura do lócus, a consciência dupla ou múltipla são estabelecidas em parte por essa diferença lógica. $\mathrm{O}$ lócus fraturado inclui a dicotomia hierárquica que constitui a subjetificação dos/as colonizados/as. Mas o lócus é fraturado pela presença que resiste, a subjetividade ativa dos/as colonizados/as contra a invasão colonial de si próprios/as na comunidade desde o habitar-se a si mesmos/as (LUGONES, 2014, p. 942-943).

Não se trata, para a autora, de priorizar o ponto de vista da/o oprimida/o, mas de considerar a multiplicidade e a coalizão no ponto da diferença. As respostas a partir dos lócus fragmentados podem estar criativamente em coalizão. Na lógica da coalizão, as diferenças não são vistas em termos dicotômicos. A multiplicidade não é reduzida (LUGONES, 2014).

Ainda na reportagem Ellen Oléria, uma multidão de minorias, a artista é descrita como sendo "minoria em, pelo menos, quatro graus distintos e entrelaçados. Ela é uma coleção, uma corporação de minorias". Isso se expressa em sua canção Linhas de Nazca: "Meu nome é encruzilhada". O verso que remete a dilemas, decisões e rituais afro-brasileiros é também uma linha demarcatória de origem (SANCHES, 2013). Assim como na prática autobiográfica de Gloria Anzaldúa (2005), em que há a tomada de uma nova consciência de si mesma como uma 
encruzilhada, ou seja, "aquela junção onde se situa a mestiça", como um local de fluxos e trânsitos, onde o corpo confunde-se com a escrita (Sonia TORRES, 2005). Anzaldúa adota uma linguagem híbrida, denotativa de um discurso polifônico, proferido por múltiplas vozes, e representativa de uma nova identidade, mestiça (CARDOSO, 2014). A palavra mestiça se refere à origem chicana de Anzaldúa, mas também à multiplicidade de suas referências identitárias. "Estoy norteada por todas las voces que me hablan simultáneamente" (ANZALDÚA, 2005, p. 704). A mestiça de Anzaldúa, com sua consciência múltipla, ocupa, em sobreposição/deslocamento, os entre lugares da diferença, resultantes dos desequilíbrios históricos e das exclusões múltiplas (COSTA E ÁVILA, 2005). Em suas palavras,

\begin{abstract}
Começei a pensar: "Sim, sou chicana, mas isso não define quem eu sou. Sim, sou mulher, mas isso também não me define. Sim, sou lésbica, mas isso não define tudo que sou. Sim, venho da classe proletária, mas não sou mais da classe proletária. Sim, venho de uma mestiçagem, mas quais são as partes dessa mestiçagem que se tornam privilegiadas? [...] Começei a pensar em termos de consciência mestiça. O que acontece com gente como eu que está ali no entre-lugar de todas essas categorias diferentes? O que é que isso faz com nossos conceitos de nacionalismo, de raça, de etnia, e mesmo de gênero? Eu estava tentando articular e criar uma teoria de existência nas fronteiras (ANZALDÚA, 2000, apud COSTA e ÁVILA, 2005, p. 691).
\end{abstract}

As fronteiras de Anzaldúa são físicas, mas também se referem às de raça, classe, gênero, orientação sexual, às fronteiras rígidas construídas pelo pensamento binário do Ocidente. A fronteira é também um local de enunciação. Anzaldúa faz uma mediação tradutória, sempre cruzando mundos e identidades. A "consciência mestiça", estrategicamente transgride parâmetros identitários, derrubando noções de "pureza", que impeçam o deslocamento e a transgressão de fronteiras simbólicas e materiais (TORRES, 2005). Seria Ellen Oléria, como Anzaldúa, uma habitante dos entre lugares da fronteira, uma tradutora de diversos mundos/grupos/referências?

\title{
7. Considerações finais
}

Sim eu já vi, se liga aqui/ Eu sobrevivi sem pena/ Só a caneta pra registrar/ O que eu não esqueci Ellen Oléria, Solta na Vida

Assim como no "lócus fraturado" de Lugones (2014), as mestiçagens múltiplas e os entre lugares das fronteiras representam, ao mesmo tempo, processos de sujeição e possibilidades de resistência e liberdade. Para Anzaldúa (2005), "o contraposicionamento refuta os pontos de vista e as crenças da cultura dominante e, por isso, é orgulhosamente desafiador" (p.705). Nesse processo, a nova mestiça é quem irá reinterpretar a história universalizante, 
recusando tanto o essencialismo identitário quanto o hibridismo hegemônico (COSTA E ÁVILA, 2005).

Como mestiza, eu não tenho país, minha terra natal me despejou; no entanto, todos os países são meus porque eu sou a irmã ou a amante em potencial de todas as mulheres. (Como uma lésbica não tenho raça, meu próprio povo me rejeita; mas sou de todas as raças porque a queer em mim existe em todas as raças.) Sou sem cultura porque, como uma feminista, desafio as crenças culturais/religiosas coletivas de origem masculina dos indo-hispânicos e anglos; entretanto, tenho cultura porque estou participando da criação de uma outra cultura, uma nova história para explicar o mundo e a nossa participação nele, um novo sistema de valores com imagens e símbolos que nos conectam um/a ao/à outro/a e ao planeta. Soy un amasamiento, sou um ato de juntar e unir que não apenas produz uma criatura tanto da luz como da escuridão, mas também uma criatura que questiona as definições de luz e de escuro e dá-lhes novos significados (ANZALDÚA, p. 707).

As perspectivas de Lugones e Anzaldúa nos levam a pensar que Ellen Oléria não apenas vivencia múltiplas opressões, mas está também em uma posição privilegiada para compreender essas opressões e resistir a elas. Mas isso não significa apenas uma melhor visão das desigualdades e a possibilidade de contraposição individual a elas. A "consciência múltipla" (LUGONES, 2014) ou a "consciência mestiça" (ANZALDÚA, 2005), derivadas da vivência das diversas diferenças inter-relacionadas, permitem que Oléria traduza suas experiências a partir de múltiplas referências culturais e sociais. Com isso, a artista pode ser representativa para vários grupos subalternizados, por meio de sua postura afirmativa. Uma voz, a partir de tantas outras vozes. No entanto, sua música questionadora, subversiva, pode ser pensada também como uma forma de criação de uma nova história, como diz Anzaldúa. O papel político de suas composições e posicionamentos é inegável. Assim como é inegável a qualidade artística de sua música. Oléria é também múltipla em talentos. Que Ellen Oléria siga "solta na vida" e registrando o que não esqueceu.

\section{Referências}

ALCÂNTARA, Fernanda. Os desafios de Ellen Oléria. Revista Raça. São Paulo: Editora Escala. Ano XVII. Ed. n. 176. Março de 2013.

ANZALDÚA, Gloria. La conciencia de la mestiza /Rumo a uma nova consciência. Estudos feministas, Florianópolis, v. 13, n.3, p. 704-719, set./dez. 2005.

BRAH, Avtar. Diferença, diversidade, diferenciação. Cadernos Pagu, Campinas, n. 26, p. 329376, jan./jun. 2006.

BRAIDOTTI, Rosi. El sujeto en el feminismo. Feminismo, diferencia sexual y subjetividade nómade. Barcelona: Editorial Gedisa, 2004, p. 9-31. 
CARDOSO, Bia. Ellen Oléria: negra, lésbica e feminista. 21/11/2011. Blogueiras Feministas. Disponível em: https://blogueirasfeministas.com/2011/11/21/ellen-oleria/. Acesso em 28/09/2015.

CARDOSO, Cláudia P. Amefricanizando o feminismo: o pensamento de Lélia Gonzalez. Estudos feministas, Florianópolis, v. 22, n. 3, p. 965-986, set./dez. 2014.

COSTA, Cláudia de L. e ÁVILA, Eliana. Gloria Anzaldúa, a consciência mestiça e o "feminismo da diferença". Estudos feministas, Florianópolis, v. 13, n. 3, p. 691-703.set./dez. 2005.

CRENSHAW, Kimberlé. Documento para o encontro de especialistas em aspectos da discriminação racial relativos ao gênero. Estudos feministas, Florianópolis, v.10, n. 01, p. 171$188,2002$.

A intersecionalidade na discriminação de raça e gênero. VV.AA. Cruzamento: raça e gênero. Brasília: Unifem, 2004.

Dicionário Cravo Albin da Música Popular Brasileira. Disponível em: http://www.dicionariompb.com.br/ellen-oleria/biografia . Acesso em 26/11/2015.

Ellen Oléria. Página oficial no Facebook. Postagens de 2015. Disponível em https://www.facebook.com/ellenoleriaOficial/. Acesso em 12/03/2016.

Ellen Oléria. Página oficial no Twitter. Postagens de 2015. Disponível em https://twitter.com/ellenoleria. Acesso em 26/02/2016.

FOUCAULT, Michel. A ordem do discurso. 12 ed. São Paulo: Edições Loyola, 1996.

GARCIA JR, Carlos Alberto Severo; VERDI, Marta Inês Machado. Interdisciplinaridade e complexidade: uma construção em ciências humanas. Revista Internacional Interdisciplinar Interthesis, Florianópolis, v.12, n.2, p.01-17, Jul./Dez. 2015.

GONZALEZ, Lélia. A categoria político-cultural de amefricanidade. Tempo brasileiro, Rio de Janeiro, n. 92/ 93, p. 69-82, jan./jun. 1988.

HALL, Stuart. Quem precisa da identidade? In: Silva, T. T. Identidade e diferença: a perspectiva dos estudos culturais. Petrópolis: Vozes, 2000, p.103-133.

A identidade cultural na pós-modernidade. 11 ed. Rio de Janeiro: DP \& A, 2011.

LAGO, Mara C. de S. Identidade: a fragmentação do conceito. In: Silva, A.; Lago, M.; Ramos, T.(Orgs.) Falas de gênero. Florianópolis: Ed. Mulheres, 1999, p. 119-129.

. De sujeitos e identidades: diálogos entre ciências humanas e psicanálise. In: RIAL, C. E TONELI, M. Juracy (Orgs.) Genealogias do silêncio: feminismo e gênero. Florianópolis: Editora Mulheres, 2004, p. 73-78.

LEON, Diego P. Entrevista com Ellen Oléria: “Sou mulher, negra, lésbica e da periferia”. Portal Uai. $30 / 12 / 2015$.

Disponível em: 
https://www.uai.com.br/app/noticia/musica/2015/12/30/noticias-musica, 175598/entrevistacom-ellen-oleria-sou-mulher-negra-lesbica-e-da-periferi.shtml. Acesso em: 15/01/2016.

LIMA, Irlam R. Poderosa: Ellen Oléria solta a voz no show de lançamento do primeiro CD, em Taguatinga. Correio Braziliense online. 02/07/2009. Disponível em: https://www.correiobraziliense.com.br/app/noticia/diversao-earte/2009/07/02/interna_diversao_arte,123177/ellen-oleria-solta-a-voz-no-show-delancamento-do-primeiro-cd-em-taguatinga.shtml. Acesso em 21/07/2015.

LUGONES, María. Rumo a um feminismo descolonial. Estudos feministas, Florianópolis, v. 22, n.3, p. 935-952, set./dez. 2014.

MOHANTY, Chandra T. Bajo los ojos del occidente: academia feminista y discurso colonial. In: NAVAZ, Liliana S. y HERNÁNDEZ, Aída (Eds.) Descolonizando el feminismo: teorias y prácticas desde las márgenes. Madrid: Ed. Cátedra, 2008.

O Globo. 29/06/2013. A revolução pessoal de uma cantora atrevida. Disponível em: https://oglobo.globo.com/. Acesso em 19/10/2015.

OLÉRIA, Ellen. Pra cima deles. Revista TPM, especial racismo, 14/04/2014. Ed. 141. Disponível em: https://revistatrip.uol.com.br/tpm/pra-cima-deles. Acesso em: 21/06/2016.

ORLANDI, Eni Puccinelli. Análise do discurso: princípios e procedimentos. 12 ed. Campinas: Pontes Editores, 2015.

PÊCHEUX, Michel. O discurso: estrutura ou acontecimento. Campinas: Pontes Editores, 2015.

PISCITELLI, Adriana. Interseccionalidades, categorias de articulação e experiências de migrantes brasileiras. Sociedade e cultura, v.11, n.2, p. 263 a 274, jul/dez. 2008.

QUIJANO, Aníbal. Colonialidade, poder, globalização e democracia. Novos rumos: Instituto Astrojildo Pereira, n. 37, p. 04-25, 2002.

SANCHES, Pedro A. Ellen Oléria, uma multidão de minorias. Revista Fórum, ed. 124. 04/08/2013. Disponível em: https://www.revistaforum.com.br/digital/124/ellen-oleria-umamultidao-de-minorias/. Acesso em 21/07/2015.

ROSA, Laila et al. Epistemologias feministas e a produção de conhecimento recente sobre mulheres e música no Brasil: algumas reflexões. In: NOGUEIRA, Isabel P.; FONSECA, Susan C. (orgs) Estudos de gênero, corpo e música: abordagens metodológicas. Goiânia/Porto Alegre: ANPPOM, 2013, p.110-137.

SANTOS, Boaventura de Sousa. Do pós-moderno para o pós-colonial. E para além de um e outro. In: VIII Congresso luso-afro-brasileiro de ciências sociais. Anais do evento. Coimbra, 2004.

SHOHAT, Ella E STAM, Robert. Crítica da imagem eurocêntrica: multiculturalismo e representação. São Paulo: Cosac Naify, 2006. 
SILVA, Tomaz T. A produção social da identidade e da diferença. In: Silva, T. T. Identidade e diferença: a perspectiva dos estudos culturais. Petrópolis: Vozes, 2000, p. 73-102.

Site artístico de Ellen Oléria. Disponível em: https://www.ellenoleria.com.br/. Acesso em: 18/06/2015.

SPIVAK, Gayatri C. Pode o subalterno falar? Belo Horizonte: Editora UFMG, 2010.

TORRES, Sonia. La conciencia de la mestiza /Towards a New Consciousness - uma conversação interamericana com Gloria Anzaldúa. Estudos feministas, Florianópolis, v. 13, n. 3, p. 720-737, set./dez. 2005. 